\title{
Un Estudio Hermenéutico De La Práctica Clínica Psicológica Contemporánea: Modelo Integrativo Supraparadigmático
}

\section{A Hermeneutic Study of the Contemporary Practice of Clinical Psychology: A Supra-paradigmatic Integrative Model}

\author{
Viviana Martínez Clavería** \\ Isaías Quinteros Carrasco \\ Universidad Santo Tomás de Chile
}

(Recepción: octubre 2004 - Aceptación: noviembre 2004)

\begin{abstract}
El quehacer concreto de la psicología no está escindido de los fundamentos teóricos explícitos e implícitos que están a la base. La práctica clínica surge para paliar los sufrimientos humanos en sus comienzos como un arte y luego como una técnica sustentada en fundamentos científicos, la psicología posee distintas maneras de realizar esta práctica. En la actualidad y en nuestro país surge el Modelo Integrativo Supraparadigmático que es una teoría-praxis destinada a resolver los problemas de la gente. Intentamos develar a este supraparadigma, reflexionar sobre esta psicoterapia y explicitar la noción de sujeto existente en ella, con el convencimiento de que teoría y praxis constituyen una unidad dialéctica indivisible y que la psicología crea un mundo en sus intervenciones.

Palabras claves: Práctica clínica, paradigma, modelo integrativo Supraparadigmático, modelo de hombre.
\end{abstract}

\begin{abstract}
The actual work of psychology is not separate from the explicit and implicit theoretical bases on which it is grounded. Clinical practice arose originally as an art meant to alleviate human suffering and then evolved into a technique based on scientific principles. There are various ways in which to carry out the practice of psychology. The Supra-paradigmatic Integrative Model, which has recently arisen in our country, is a theorypraxis for solving people's problems. We attempt to explain this supra-paradigm, reflect on this type of psychotherapy, and clarify its notion of subject, with the conviction that theory and praxis constitute an indivisible dialectic and that the practice of psychology creates a world.
\end{abstract}

Key words: Clinical practice, paradigm, Supra-paradigmatic Integrative Model, human model.

\section{1.- Introducción}

Desde sus comienzos el conocimiento humano ha estado orientado a la comprensión del mundo, en por lo menos dos vertientes: la primera destinada a la producción de un saber acerca de él y la segunda destinada a la construcción de herramientas para su modificación. Desde la antigua Grecia, se distinguía entre episteme o saber puro y techné o arte práctico; diferen-

\footnotetext{
** Psicóloga, Licenciada en Psicología, Universidad Santo Tomás. Terapeuta Ocupacional, Universidad de Chile. Correspondencia: Universidad Santo Tomás (Sede Talca), Av. Carlos Schorr 255. Talca-Chile. FonoFax: 071 226515- 071226756 - 071 233686. E-mail: psi_vmartinez@hotmail.com.

1 BUNGE, citado en MOLINARI, Juan M. "PSICOLOGIAA CLÍNICA EN LA POSMODERNIDAD: PERSPECTIVAS DESDE EL CONSTRUCCIONISMO SOCIAL". Revista Psykhe. Vol 12 (1). 3-15, 2003. Pág. 3.
}

ciando también la theorein referida a la contemplación de la praxis o actividad dirigida al cambio. La ciencia, desde sus orígenes ha buscado entender el mundo, (la tecnología) por su parte, proporciona herramientas para modificarlo. "Entre el saber puro y las herramientas de intervención que se le derivan se encuentra la ciencia aplicada, una suerte de puente que comunica ambos reinos." Existe entonces un hilo conductor entre ciencia básica, ciencia aplicada y tecnología que une los rasgos de la realidad y las herramientas que se elaboran para intervenir en ella ${ }^{2}$ como una unidad dialéctica.

Podemos establecer que en los esfuerzos de modificación del medio, y lo relativo a cambiar aspectos del ser humano, en particular sus pa-

2 Op. Cit: 1. Pág. 3. 
decimientos, nace la clínica ${ }^{3}$ como forma de saber práctico, el cual se dedica a la búsqueda de las técnicas que proporcionen alivio o curación al individuo categorizado como enfermo. En sus inicios y hasta principios del siglo XI, la medicina fue actividad preferentemente priva$\mathrm{da}$, que se ejercía en la casa del paciente o en el consultorio del médico. "Durante mucho tiempo, sin duda, la experiencia médica permaneció abierta, y supo encontrar, entre el ver y el saber, un equilibrio que la protegió del error: 'En los tiempos remotos, el arte de la medicina de su objeto y los jóvenes aprendían la ciencia médica en el lecho del enfermo'; éstos, con mucha frecuencia, estaban alojados en el domicilio mismo del médico, y los alumnos acompañaban a los maestros, mañana y tarde, a la visita de sus clientes." 4

Sin embargo, el conocimiento obtenido desde la práctica clínica junto al enfermo, comienza a ser disociado de la relación inmediata y a quedar en manos de un grupo privilegiado $^{5}$. La clínica, pretende abandonar su cualidad de arte, interpretativo, y pretende convertirse en una técnica que ya no depende del saber hacer del artesano, sino de un ritual de movimientos inspirados en un modelo

\footnotetext{
3 "La palabra clínica proviene de la voz griega Kliné, que significa cama, que a su vez deriva del verbo klinéin (inclinarse). Ambos provienen de la raíz indoeuropea kli, que significa inclinarse (junto a la cama). Esto indicaba la frecuencia con que el médico acudía al domicilio del enfermo y lo atendía mientras éste estaba acostado en su cama. El médico clínico era aquel que atendía a su paciente en la cabecera de la cama. Actualmente, designa al médico que atiende directamente a sus pacientes, no necesariamente en el lecho, sino también en un hospital consultorio". PEREZ-TAMAYO, Ruy. "EL EJERCICIO ACTUAL DE LA MEDICINA". Consejo de Salubridad General, México, 1996-2003. Consultado en octubre, 25, 2003 en http//www.salud.gob.mx/unidades/csg/publica/ libros/ejercicio/.html.

4 FOUCAULT, Michel. "EL NACIMIENTO DE LA CLÍNICA, UNA ARQUEOLOGÍA DE LA MIRADA MÉDICA". Traducción de Francisca Penjo. Editorial Siglo XXI. México, 1996. Pág. 86.

5 "Mucho antes de terminar el siglo XVIII, existía la clínica [...] antes de ser un saber, la clínica era una relación universal de la humanidad consigo misma. Y la decadencia comenzó cuando fueron inaugurados la escritura y el secreto, es decir, la repartición de este saber en un grupo privilegiado, y la disociación de la relación inmediata, sin obstáculo ni límites, entre mirada y palabra: lo que se había sabido no se comunicaba ya a los demás y vestido de nuevo en la cuenta de la práctica sino una vez pasado el esoterismo del saber". Op. Cit. 4. Pág. 85.
}

teórico previo al fenómeno sobre el que se quiere actuar y que, por tanto, no depende de él ${ }^{6}$.

La clínica se transforma en su práctica, desde mediados del siglo XVII, de la anterior Ars medica $^{7}$. Se crean espacios clínicos diferenciados dentro de los hospicios generales ${ }^{8}$, cuya finalidad era la docencia del arte de sanar, utilizando la misma metodología que estaban siguiendo otras ciencias de la época, en particular las denominadas ciencias de la naturaleza, las cuales instauraron un modelo mecanicista de la naturaleza, esencial para la ciencia desde los trabajos de Galileo y Descartes, y más en concreto después de la física mecánica de Newton, cuyo fin último era mostrar el funcionamiento de los fenómenos de la naturaleza como regulados por leyes matemáticas que permitían comprender sus causas y anticipar sus efectos. ${ }^{9}$

Vemos así, cómo la práctica clínica tiene su origen en un momento histórico en que la cultura europea se encuentra en un proceso de ruptura epistemológica, la cual es producida principalmente por la nueva forma de estudiar la naturaleza de Galileo que inspiró la separación entre el sujeto que pretende conocer las leyes de la naturaleza y su objeto de estudio, diferenciación introducida por el cogito cartesiano, que separará definitivamente los discursos de la ciencia y la filosofía. ${ }^{10}$

6 ROCAI SEBASTIÁ, Françesc. “¿ES LA PSIQUIATRÍA UNA CIENCIA?”. Revista de la Asociación Española de Neuropsiquiatría Vol. 19 (72), 1999. Pág. 609.

7 "Ars designa en latín toda destreza o habilidad que se atiene a las leyes de un oficio (arte del orador, del alfarero, del soldado, del jurista, del geómetra, etc.). Ars se aproxima a lo que nosotros llamamos "técnica"; no en vano este vocablo proviene del griego techné que significa sustancialmente lo mismo que el ars latino. En la antigüedad clásica ars y techné se traducían entre sí con facilidad. Pues bien, desde el siglo V a. c. hasta el Renacimiento no hubo en Occidente otro concepto de arte que el de ars/techné". PRIETO, Pablo (2003). “ARTE". Consultado en octubre 29, 2003, en: http://www.almudi.org/ App/Asp/Noticias/noticias.asp? $n=414$.

8 "Esta tradición empezó a modificarse con el surgimiento de los primeros hospitales, que al principio eran más bien asilos para peregrinos y gente pobre que se encontraba en camino y no tenía donde dormir, atendidos por religiosos que de este modo cumplían con el mandato de la caridad cristiana". FOUCAULT, Michel. "LA HISTO. RIA DE LA LOCURA". Editorial Fondo de Cultura Económica. México, 1998. Volumen I. Pág. 182.

9 "La medicina moderna ha fijado su fecha de nacimiento hacia los últimos años del siglo XVIII. Cuando reflexiona sobre sí misma, identifica el origen de su positividad a una vuelta, más allá de toda teoría, a la modestia eficaz de lo percibido". Op. Cita 4. Pág. 4.

${ }^{10}$ Op. Cit. 6. Pág. 612. 
Es así, como es introducida una nueva forma de razonamiento la cual pretende describir con exactitud los fenómenos a los que hace referencia, con la finalidad de deducir los principios que causan un fenómeno patológico, llegando a la búsqueda de la máxima rigurosidad al operacionalizar los diferentes términos, ligándolos a su etimología clásica. Esta construcción de un lenguaje común, fue necesaria para la enseñanza en las escuelas clínicas y la construcción de un saber de las enfermedades ${ }^{11}$, que pudiere ser transmitido de unos médicos a otros, pretendiendo trasmitir el saber concerniente al paciente como una verdad absoluta, olvidándose de la ontología del individuo enfermo. ${ }^{12}$

Así, podemos pensar que la medicina, con el comienzo de la práctica clínica, se convierte en una ciencia descriptiva de las enfermedades, una ciencia nosográfica cuya finalidad es señalada como la de definir un conjunto cerrado de síntomas y signos observables en un enfermo ${ }^{13}$ y enunciar su ley interna con el establecimiento de dicho conjunto, es decir, la etiología de la enfermedad en si ${ }^{14}$, de esta manera vemos el paso de una medicina práctica a una medicina científica que llegará a utilizar como modelo de construcción del conocimiento el método experimental.

En la actualidad, en psicología existen diferentes teorías y modelos que sustentan la práctica clínica, uno de estos modelos en boga en estos momentos y generado por profesionales chilenos, es el Modelo Integrativo Supraparadigmático, planteado por Roberto $\mathrm{Opazo}^{15}$. Tomaremos este Modelo, a modo

11 "El rigor descriptivo será la resultante de una exactitud en el enunciado y de una regularidad en la denominación, que es, según Pinel, 'El método seguido ahora en todas las demás partes de la historia natural'. Así el lenguaje se encuentra cargado de una doble función: por su valor de exactitud, establece una correlación entre cada sector de lo visible y un elemento enunciable, en el interior de su papel de descripción, hace desempeñar una función denominadora que, por su articulación en un vocabulario constante y fijo, autoriza la comparación, la generalización, y la colocación en el interior de un conjunto". Op. Cit. 4. Págs. 164-165.

${ }^{12}$ Op. Cit. 6. Pág. 612.

13 "Es la descripción, o más bien la labor implícita del lenguaje, en la descripción que autoriza la transformación del síntoma en signo, el paso del enfermo a la enfermedad, el acceso de lo individual a lo conceptual". Op. Cit. 4. Págs. 164-165.

${ }^{14}$ Op. Cit. 6. Pág. 614.

${ }^{15}$ Psicólogo Universidad Católica de Chile. Doctor en Psicología Universidad Nacional de San Luis. Fundador del Centro Científico de Desarrollo Psicológico (CECIDEP). Fundador del Instituto Chileno de Psicoterapia Integrativa (ICPSI). de ejemplo, para ver cómo en la práctica clínica la praxis y la teoría son indivisibles, en este caso en la práctica clínica de la Psicoterapia Integrativa.

\section{2.- Psicoterapia Integrativa, Un Modelo Contemporáneo De Práctica Clínica.}

Dentro de las diversas corrientes clínicas de la psicología, en los últimos años han surgido esfuerzos por integrar conocimientos en la práctica clínica, es así, como a finales de los años 80 ' surge en nuestro país un modelo integrativo, que se propone ser una "teoría/ práctica que ha venido enriqueciendo el trabajo clínico y posibilitando el desarrollo de la psicoterapia integrativa."16

A continuación mostraremos algunos aspectos de este modelo, utilizando la descripción que realiza Opazo, "es importante enfatizar el hecho que el Modelo Integrativo no integra enfoques, ni autores, integra paradigmas. Esto, sin embargo, no significa no 'rescatar' con entusiasmo los aportes valiosos de cada enfoque o no 'rescatar' los aportes valiosos de cada autor."17 El Modelo se construye sobre la base de paradigmas, desde donde, se busca generar conocimiento por diferentes vías.

El objetivo de lo anterior para el Modelo Integrativo Supraparadigmático es aportar el espacio suficiente para que los distintos componentes y sus influencias tengan cabida en él; la búsqueda de comprender la dinámica psicológica sin exclusiones y sin puntos ciegos, de esta manera no se deja afuera de la estructura, algún elemento que pudiera contribuir a la comprensión, a la predicción o al cambio.

En el Modelo Integrativo se pretende construir un todo a partir de partes diferentes; encontrando respuestas articuladas a conjuntos que son diversos y complejos, de esta forma la integración de paradigmas inconexos procura ser más que una mera sumatoria, intentando crear una unidad funcionalmente relacionada, comunicada e integrada.

Este Modelo “integra los paradigmas biológico, ambiental /conductual, cognitivo, afectivo, inconsciente y sistémico, en una unidad coherente Supraparadigmática. El eje integrador

${ }^{16}$ OPAZO, Roberto. "PSICOTERAPIA INTEGRATIVA. DELIMITACIÓN CLÍNICA”. Ediciones ICPSI. Santiago de Chile, 2001. Pág. 46.

17 Op. Cita 16. Pág. 117. 
del Modelo es el sistema Self el cual constituye el punto de confluencia de los sub-sistemas o paradigmas. En el Modelo predominan los continuos con acentuación y no las fronteras rígidas; así, por ejemplo, una acentuación cognitiva no implica una ausencia total de afecto y viceversa. El sistema Self es a su vez un continuo que va desde lo más nuclear a lo más periférico (que incluye a la persona como totalidad)."18

El Sistema Self "es el punto central de la experiencia y constituye el eje de integración de los sub-sistemas biológico, ambiental/ conductual, cognitivo, afectivo e inconsciente." ${ }^{\prime 19}$ Siendo sus funciones: Función de Identidad, Función de Auto-Organización, Función de Significación y Función de Control Conductual.

Otros elementos mencionados en el Modelo Integrativo son: Causalidad Lineal, Causalidad Circular, Mecanismos de Retroalimentación y Procesos Constructivos en la Significación.

Los elementos anteriores se configuran estructuralmente en el siguiente modelo.

Según lo planteado por Opazo, "en el Modelo $\mathrm{E}$ son los estímulos ambientales, $\mathrm{P}$ es la persona, $\mathrm{C}$ es la conducta abierta, $\mathrm{K} 1$ son las consecuencias inmediatas y $\mathrm{K} 2$ son las consecuencias mediatas. El eje integrador de la persona (P) es el sistema SELF, hacia el cual convergen los paradigmas biológico, cognitivo, afectivo e inconsciente. El Modelo integra también las modalidades causales lineal (Æ) y circular (?). El Modelo asume la importancia tanto de las partes como del todo; el supuesto subyacente del Modelo en este ámbito sería 'ni sólo los árboles, ni sólo el bosque, sino ambos'». ${ }^{20}$

\section{3.- Análisis Epistemológico Del Modelo Integrativo} Supraparadigmático.

\section{1.- El Paradigma del Supraparadigma}

Lo primero que queremos analizar es el concepto de paradigma utilizado por el Modelo "un marco conceptual amplio y compartido, que aporta planteamientos básicos en tér-

${ }^{18}$ Op. Cit. 16. Pág. 118. Para mayor comprensión de este Modelo recomendamos la lectura del Texto "PSICOTERAPIA INTEGRATIVA. DELIMITACIÓN CLÍNICA". Ediciones ICPSI. Santiago de Chile, 2001.

${ }^{19}$ Op. Cit. 16. Pág. 116.

${ }^{20}$ Op. Cit. 16. Págs. 117 y ss. minos epistemológicos, metodológicos y etiológicos, que es capaz de orientar la investigación que puede servir de fundamento a una aproximación psicoterapéutica que le sea consistente. A su vez, un 'supraparadigma' es capaz de integrar paradigmas o marcos conceptuales menos abarcativos."21

Según Kuhn, un paradigma significa "toda la constelación de creencias, valores, técnicas, etc., que comparten los miembros de una comunidad dada. Por otra parte, denota una especie de elemento de tal constelación, las concretas soluciones de problemas que, empleadas como modelos o ejemplos, pueden reemplazar reglas explícitas como base de la solución de los restantes problemas de la ciencia normal." 22 También señala que "un paradigma es lo que comparten los miembros de una comunidad científica $y$, a la inversa una comunidad científica consiste en unas personas que comparten un paradigma." ${ }^{23}$

Sin embargo, Kuhn afirma que las ciencias sociales entre ellas la psicología, son ciencias inmaduras o preparadigmáticas, es decir, no existe ningún paradigma que logre convocar a sus científicos para aplicarlo como una regla única que dé solución a los problemas de la ciencia. En este sentido, en la práctica clínica de la psicoterapia vemos distintas teorías que intentan dar explicación y solución a los problemas de la disciplina, pero cada una de ellas tiene distintos supuestos epistemológicos, metodológicos, y prácticos incompatibles entre sí, hecho que Opazo reconoce. ${ }^{24}$ Por lo tanto, no existen paradigmas en la psicología y no existiendo estos, es poco probable que pueda sustentarse la idea de supraparadigma. Éste no puede entenderse como reunión de paradigmas, ni tampoco como la articulación de partes de ellos; menos aún como algo que esté sobre los paradigmas, porque ello implicaría el nacimiento de un nuevo paradigma.

\footnotetext{
${ }^{21}$ Op. Cit. 16. Pág. 45.

${ }^{22}$ KUHN, T. S. "LA ESTRUCTURA DE LAS REVOLUCIONES CIENTÍFICAS”. Fondo de la Cultura Económica Chile S.A. Santiago de Chile, 1993. Pág. 269.

${ }^{23}$ Op.Cit. 22. Pág. 271.

24 "En el contexto descrito cualquier proposición de un paradigma integrativo, tiene las máximas probabilidades de ser muy descalificado, sobre la base de discrepancias epistemológicas y paradigmáticas, etc. El problema es que sobre esta base, la espera se puede prolongar demasiado y las cosas no están para grandes esperas". OPAZO, Roberto. "INTEGRACIÓN EN PSICOTERAPIA". Ediciones CECIDEP. Santiago de Chile, 1992. Pág. 412.
} 
Esta imposibilidad de comparación entre paradigmas y de sustento de un supraparadigma, se relaciona también con el concepto de inconmensurabilidad planteado por Kuhn, en el cual se señala que no se puede comparar dos paradigmas sobre una base en común porque no hablan de lo mismo, con lo cual la decisión de elegir uno de ambos responde menos a una elección racional que a una conversión de tipo religioso. ${ }^{25}$ "La inconmensurabilidad de los paradigmas impediría la posibilidad de discusiones neutrales, pues un lenguaje 'neutral' estaría inserto en una especie de paradigma absoluto desde el cual se podrían discutir los demás, lo cual, de hecho, sería imposible en razón del carácter sociológicamente relativo de la noción de 'paradigma' que Kuhn ofrece."26

Inclusive, dos paradigmas rivales pueden utilizar las mismas palabras, pero, al asignar a esas palabras significados diferentes, jamás podrán ponerse de acuerdo entre sí para ver quién tiene razón, ya que el significado de un término reside en cómo está articulado sintácticamente con otros términos, "las palabras toman su significación [...] del modo como ellas se articulan entre sí. El significado de los términos es posterior a la existencia del lenguaje con totalidad, pues sería esa totalidad la que otorga significado a los términos particulares." ${ }^{27}$ Así, Kuhn establece que "en el nuevo paradigma, los términos, los conceptos [...] entran en relaciones diferentes unos con otros. El resultado inevitable es lo que debemos llamar, aunque el término no sea absolutamente correcto, un malentendido entre las dos escuelas en competencia." ${ }^{28}$ Esto lo vemos, en que la idea de inconsciente es muy distinta desde la visión de los psicoanalistas ${ }^{29}$, a la idea de inconsciente propuesta por Opazo. ${ }^{30}$

\footnotetext{
25 "Ni las buenas razones, ni la traducción constituyen la conversión, y éste es el proceso que debemos explicar con objeto de entender una clase esencial de cambio científico". Op. Cit. 22. Págs. 311-312.

${ }^{26}$ KLIMOVSKY G., "LAS DESVENTURAS DEL CONOCIMIENTO CIENTÍFICO (UNA INTRODUCCIÓN A LA EPISTEMOLOGÍA)". A-Z Editora, Buenos Aires, 1994, Pág. 362.

${ }^{27}$ Op. Cit. 26. Pág. 52.

${ }^{28}$ Op. Cit. 22. Pág. 231.

29 "E1 inconsciente freudiano es ante todo e indisolublemente una noción tópica y dinámica, deducida de la experiencia de la cura. Ésta ha mostrado que el psiquismo no es reductible a lo consciente y que ciertos 'contenidos' sólo se vuelven accesibles a la conciencia una vez que han superado las resistencias [...] El inconsciente es un 'lugar psíquico' particular que es preciso
}

- Con lo anterior vemos cómo la visión supraparadigmática, es capaz de definir a otro paradigma (según la definición de Opazo, según nuestro enfoque teórico ${ }^{31}$ ), desde el paradigma propio $^{32}$ (enfoque teórico), a nuestro juicio el único paradigma que sustenta al modelo integrativo al igual que a otros enfoques como la corriente conductual, la cognitiva, la cognitiva-conductual, es el positivismo, y el supraparadigma de este modelo lo que intenta es adaptar las corrientes no positivistas, entendiendo e integrándolas a una mirada positivista. Esto lo podemos observar a través del análisis de su metodología.

Opazo define que lo que distingue a un conocimiento utilizable de otro, es que aporte a la predicción y al cambio terapéutico ${ }^{33}$, así mismo, plantea que el conocimiento debe ser acumulable, que se deben rescatar datos que sirvan para la investigación del conocimiento científico $^{34}$, y concuerda con lo que señala Piaget

representarse, no como una segunda conciencia, sino como un sistema que tiene contenidos, mecanismos y posiblemente una 'energía' especifica". LAPLANCHE, Jean y PONTALIO Jean-Bertrand. "DICCIONARIO DE PSICOANÁLISIS". Editorial Piados SAICF. Buenos Aires, 2001. Pág. 194.

30 "Lo que define a lo inconsciente es que sea desconocido para la consciencia”. Op. Cit. 16. Pág. 114.

31 "Principio y marco teórico que proporciona los supuestos básicos sobre el funcionamiento de las personas y brinda categorías que permitirán a los clínicos detectar y ubicar los temas centrales y los aspectos fundamentales de los actos de las personas, y sus contextos vitales". KENDALL, Philip y NORTON-FORD, Julian. "PSICOLOGÍA CLÍNICA". Editorial Limusa S.A. Cuidad de México, 1988. Pág. 165.

${ }^{32} \mathrm{Sin}$ embargo, queremos señalar la defensa a la propia autocrítica que realiza Opazo, en relación a la utilización de teorías y estrategias que han sido apartadas de su ambiente semántico original. Opazo señala que no está demostrado que estas teorías pierdan algún valor en el transplante, "más aun, incluso podrían ser sinergizadas positivamente en el nuevo contexto. Cuando los kiwis fueron 'transplantados' desde su hábitat natural en China o Nueva Zelandia hacia Chile o California, se vieron fortalecidos con el cambio de contexto. Por su parte Bruce Lee (1940-1973), actor y especialista en artes marciales, creó el Jeet Kune Do seleccionando los mejores 27 estilos de lucha, y apartando cada 'extracto' de su hábitat original; el nuevo estilo supera con creces el de los anteriores". Op. Cit. 16. Págs. 339-340.

33 "El valor del conocimiento puede así establecerse no ya sobre la base de discusiones teóricas o lógicas sino sobre la base de la acción, es decir, de su aporte para la predicción y para el cambio terapéutico". Op. Cit. 24. Pág. 428. 


\section{MARTÍNEZ, QUINTEROS}

en cuanto a "posponer la discusión de los grandes problemas que nos separan, y dedicarnos a buscar acuerdos y a 'acumular hechos verificables y unánimemente reconocidos a propósito de cada problema bien delimitado"35; también señala que "la verdad en ciencia es probabilística; siempre reemplazable por una verdad más probable. Pero el científico lucha por acercarse en la mayor medida posible a cómo las cosas son"36, en esto Opazo realiza el mismo planteamiento que Popper, en cuanto a que la verdad es siempre gradual y que el conocimiento científico nunca puede alcanzarla plenamente, sin embargo, el conocimiento científico es el modelo más perfecto de conocimiento. ${ }^{37}$

No obstante, Opazo agrega "no creo que los científicos se esforzarían sobre la base de un deseo de satisfacer los criterios de la ciencia, acordados con otros científicos; más bien creo lo contrario; los criterios científicos de predicción, réplica, verificación, observaciones independientes, etc. constituyen esfuerzos denodados para ganar en objetividad. La búsqueda de objetividad es así la esencia del conocimiento científico. Un agnosticismo respecto a la objetividad, quita todo sentido profundo al conocimiento"38; en esto Opazo se aleja del racionalismo crítico de Popper, ya que éste tiene como planteamiento central la necesidad de que la ciencia se someta a los procedimientos de refutación, además de "realizar un considerable esfuerzo al criticar algunas de la categorías centrales del positivismo clásico como su nexo con la empiria, sus procesos de verificación, la propia noción de teoría, la lógica de la investigación y los pasos a seguir."39 Opazo entonces asume la postura del positivismo clásico.

\footnotetext{
34 "Favorecer una actitud científica [...] lo cual involucra exigir rigor metodológico, valorar los datos de la investigación y nutrirse de ellos 'a perpetuidad' [...] sólo con el trasfondo permanente de esa actitud, pasan a tener sentido planteamientos científicos como los conocimientos probabilísticos replicables, los follow-up, los conocimientos acumulables". Op. Cit. 16. Pág. 69.

${ }^{35}$ Este conocimiento verificable es lo que siempre busca el positivismo. Op. Cit. 24. Pág. 418.

${ }^{36}$ Op. Cit. 24. Pág. 420.

${ }^{37}$ POPPER, Karl. "EL DESARROLLO DEL CONOCIMIENTO CIENTÍFICO. CONJETURAS Y REFUTACIONES”. Ediciones Paidós, Buenos Aires, 1964. Pág. 250.

${ }^{38}$ Op. Cit. 24. Pág. 421.

${ }^{39}$ MATUS, Teresa. "PROPUESTA CONTEMPORÁNEAS EN TRABAJO SOCIAL, HACIA UNA VISIÓN POLIFÓNICA". Editorial Espacio. Buenos Aires. Argentina, 1999. Pág. 57.
}

Asimismo, Opazo desde su postura positivista, critica a los enfoques que no han podido realizar demostraciones de lo que sustentan, como el psicoanálisis, el enfoque sistémico y el enfoque procesal sistémico, donde la evidencia es inexistente ${ }^{40}$. Como señala Foucault, "No sería la pregunta ¿qué tipos de saberes queréis descalificar en el momento en que decís; esto es una ciencia?, ¿qué sujetos hablantes, charlantes, qué sujetos de experiencia y de saber queréis 'minorizar' cuando decís: hago este discurso, hago un discurso científico, soy un científico?, ¿qué vanguardia teórico-política queréis entronizar para demarcarla de las formas circundantes y discontinuas del saber? ${ }^{41}$

Por todo lo anterior y aunque este Modelo no lo declare abiertamente, es posible y se nos hace evidente que el método utilizado por este Modelo es el método empírico experimental al estilo de las ciencias naturales, y aunque se señale que todos los métodos son legítimos, creemos que el conocimiento escogido preferentemente, por obtener un conocimiento válido y comprobable, para este Modelo es aquel que es producto de este tipo de metodología.

Brunet ha señalado que "es preciso someter a la metodología a la interrogación epistemológica ya que cualquier técnica, incluso la más aparentemente neutral contiene una

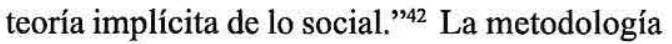
que estamos vislumbrando utiliza, la razón instrumental, la cual se orienta por reglas técnicas que descansan sobre el saber empírico. Estas reglas conllevan pronósticos sobre hechos observables de naturaleza física o social. Al ejercer una elección racional, esta se sustenta en estrategias que se basan en un saber analítico, implicando deducciones de sistemas de valores y máximas generales, organizando medios que resulten adecuada o inadecuados, según los criterios para una control eficiente de la realidad..$^{43}$

El método científico, ha dominado en la conciencia de los científicos, como la única forma de obtener conocimiento verdadero. Se va

${ }^{40}$ Op. Cit. 16. Pág. 66.

${ }^{41}$ FOUCAULT, Michel. "MICROFÍSICA DEL PODER". Ediciones de la Piqueta. Madrid, 1992. Pág. 131.

${ }^{42}$ BRUNET, Ignasi y VALERO, Luis. "EPISTEMOLOGÍA Y SOCIOLOGÍA DE LAS CIENCIAS”. Promoción y publicaciones Universitarias S.A. Barcelona, 1996. Pág. 465.

${ }^{43}$ HABERMAS, Jürgen. "CIENCIA Y TÉCNICA COMO IDEOLOGIA". Editorial Tecnos S.A. Madrid, 1999. Pág. 68. 
instaurando como un pensamiento dominante en nuestros tiempos. El Modelo Integrativo se acerca a esta visión de adquirir conocimiento, al no cuestionar este modo dominante de razonar, y asumirlo como dado, siendo parte del cientifismo de nuestra época que implica el convencimiento de que ya no se puede entender la ciencia como una forma de conocimiento posible, sino que se identifica a la ciencia con el conocimiento. ${ }^{44}$

La ciencia es una forma global de producción, que va definiendo la cultura, y crea un mundo volviéndose totalizadora. ${ }^{45}$ Primero domina a la naturaleza y luego a través de ésta, domina al hombre. Hoy la dominación no es solo por medio de la tecnología, sino cómo la tecnología. Entendiendo por técnica "la capacidad de disposición científicamente racionalizada sobre procesos objetivados"46 y que está relacionada intimamente con la investigación y ambas a su vez, conectadas con la economía y la administración y retroalimentadas por ellas.

La ciencia y la técnica se presentan como una unión fructífera que se consolida con el tiempo. Se ha hecho común entre los investigadores el término "tecnociencia" ${ }^{47}$, el cual expresa esta relación. En nuestra época la técnica se hace científica, puesto que busca solamente en la ciencia su fundamentación e impulso, y asimismo, la ciencia se hace también tecnológica cuando su desarrollo se hace impensable sin un progreso de la técnica. El instrumental técnico que el científico actual necesita en sus investigaciones, no es suficiente ya que se añade el hecho de que la sociedad se muestra muy reacia a financiar líneas de investigación que no tengan aplicaciones técnicas rentables a corto plazo. Por lo anterior, los científicos saben que su reconocimiento profesional depende en mucho de la efectividad práctica de sus descubrimientos. ${ }^{48}$

Bajo esta premisa de que la ciencia necesita hoy de la técnica para desarrollarse y debe producir técnica para financiarse, el Modelo de Opazo, podría estar realizando un tipo de tecnociencia que aporta en la solución de los problemas concretos y urgentes de la personas,

\footnotetext{
${ }^{44}$ DIÉGUEZ, Antonio J. “CIENTIFISMO Y MODERNIDAD: UNA DISCUSIÓN SOBRE EL LUGAR DE LA CIENCIA". Revista Interdisciplinaria de Filosofia "El Giro Postmoderno". Suplemento 1, 1993. Pág. 2.

${ }^{45}$ Op. Cit. 44. Pág. 58.

${ }^{46}$ Op. Cit. 44. Pág. 123.

${ }^{47}$ Op. Cit. 45. Pág. 4.

${ }^{48}$ Op. Cit. 45 . Pág. 4.
}

señalando "en todo caso, no veo grandes ventajas en prolongar una discusión a la que la filosofía ha dedicado siglos sin llegar a conclusiones definitivas. Y, aunque considero muy importante los fundamentos epistemológicos de la psicoterapia, la toma de posiciones siempre implicará una base de incertidumbre. Al ser esto así, las discusiones sobre el tema se podrían prologar indefinidamente y nuestros pacientes no disponen de tanto tiempo." 49

En el Modelo Integrativo se señala "es cierto que podemos dudar de todo y luego dudar de nuestras dudas en un proceso interminable que Descartes recorrió hace ya mucho. En el íntertanto, sin embargo, alguien tiene que ocuparse de las personas y de sus problemas, aun asumiendo el riesgo que los problemas sean ficticios y que las personas ni siquiera existan." 50 Con esto, se define la prioridad pragmática y entonces técnica del modelo, lo cual también se observa en la autodefinición que se realiza del modelo, como una teoría/práctica ${ }^{51}$. Con lo cual se confirma lo planteado por Habermas en cuanto a que la ciencia moderna debe ser considerada como una ciencia obligada a mantener la actitud de una posible disposición técnica. ${ }^{52}$

La técnica es moldeada, según el momento histórico, los intereses y los valores predominantes de una determinada época ${ }^{53}$; como señala Weber "la técnica es en cada caso un proyecto histórico social: en él se proyecta lo que una sociedad y los intereses en ella dominantes tienen el propósito de hacer con los hombres y con las cosas." ${ }^{54}$ En nuestra disciplina las teorías psicológicas básicas y aplicadas y las psicotecnologías no son invenciones separadas de su nicho social, son repercutidas por la dinámica de la sociedad en la cual fueron creadas, y afectadas por un conjunto de factores extracientíficos: la cultura, la economía, la po-

\footnotetext{
${ }^{49}$ Op. Cit. 24. Pág. 421.

${ }^{50}$ Op. Cit. 24. Pág. 420.

s1 Op. Cit. 16. Pág. 46.

52 Op. Cit. 44. Pág. 62.

53 "El conocimiento científico no difiere sustancialmente de otros tipos de conocimiento, salvo por su mayor eficacia en la resolución de problemas. No es de extrañar esta función instrumental y pragmática dado que con los productos científicos se busca obtener determinados objetivos y satisfacer ciertos intereses. Por tanto, el conocimiento científico que se tiene por verdadero se modula a partir de la realización de esta tarea indisolublemente ligada a la ciencia". LAMO de Espinosa citado en Op. Cit. 42. Pág. 383.

${ }^{54}$ WEBER citado en Op. Cit. 44. Pág. 55.
} 


\section{MARTÍNEZ, QUINTEROS}

lítica. ${ }^{55}$ Este proyecto histórico social puede desaparecer de la conciencia de la población, quienes se entregan a la promesa que éste realiza: una vida más confortable. ${ }^{56}$

Desde el modelo integrativo podemos inferir que la promesa de éste es la capacidad de predecir el comportamiento humano y de provocar el cambio terapéutico, además de entregar soluciones concretas y prácticas a las personas, pues considera urgente entregar respuestas ahora, para que las personas puedan llevar mejor sus vidas.

Asimismo, la promesa del Modelo Integrativo hacia la sociedad podría ser el constituirse en una práctica clínica eficiente que devuelva la funcionalidad a los individuos, "si podemos ir identificando aquellas fuerzas de cambio que resulten más potentes en determinadas circunstancias, podremos aspirar a producir un mayor cambio terapéutico, en un menor tiempo y con un menor costo energético y económico" ${ }^{\$ 7}$, lo anterior tendiendo a la inserción eficaz en el nicho social ${ }^{58}$; utilizando para ello lo que Marcuse señala como la racionalidad, la cual se refiere "a la correcta elección entre estrategias, a la adecuada utilización de tecnologías y a la pertinente instauración de sistemas." 59

Vemos entonces como la ciencia y la técnica misma "en la forma de una conciencia positivista imperante -articulada como conciencia tecnocrática- asumen el papel de una ideología que sustituye a las ideologías burguesas destruidas." ${ }^{60}$ Así lo señalan Horkheimer y Adorno en la Dialéctica de la Ilustración, y es llevado al extremo por Marcuse cuando señala que "la ciencia y la técnica se convierten ellas mismas en ideológicas." ${ }^{61}$ Así, la ciencia se caracteriza por formular problemas cuyas soluciones están predeterminadas, elaboradas más allá del proceso cognoscitivo. ${ }^{62}$

${ }^{55}$ Op. Cit. 1. Pág. 6.

${ }^{56}$ Op. Cit. 44. Pág. 56.

${ }^{57}$ Op. Cit. 24. Pág. 431.

58 "En el campo disciplinar de la psicología, el conocimiento de la mente humana ha dado lugar al surgimiento de tecnologías cuyo propósito es la modificación de la conducta, entendida ésta en sentido lato". Op. cita 1. Pág. 6.

${ }^{59}$ MARCUSE señala que a través de la racionalidad se impone una determinada forma de dominio. Ver en Op. cita 44. Pág. 54.

${ }^{60}$ Op. Cit. 44. Pág. 102.

${ }^{61}$ Op. Cit. 44. Pág. 102.

62 "Las preguntas ideológicas constituyen un espejo en el que el sujeto ideológico puede reconocer sus propias respuestas ideológicas". Op. Cit. 42. Pág. 383.
Como señala Barnes "el conocimiento no puede ser entendido más que como el producto generado por hombres que operan en términos de un interés en la predicción y el control conformado por lo específico de su situación"63 entonces, el conocimiento está dirigido por intereses, ya que la actividad científica no la practican sujetos epistémicos ideales, por el contrario, es realizada por grupos sociales concretos, consensualmente llamados comunidades científicas, las cuales generarán un tipo de conocimiento, que permitirá establecer y mantener el orden social, a través de la mantención de la distribución del poder dentro de una sociedad.

Una sociedad es un conjunto ordenado de poderes en virtud de que es una distribución de conocimientos. Al especificar lo que saben los miembros de la misma, se determina cuáles son los poderes de que dispone su sociedad, y quienes de entre todos sus miembros, son los que tienen discreción en su uso.

En el Modelo Integrativo, podemos apreciar la importancia que le otorga Opazo a la obtención de cierto tipo de conocimiento científico para la psicología, señalando cuál es la distribución de conocimiento y entonces de poder que le corresponde a esta disciplina, también al expresar que el conocimiento de la causalidad es imprescindible, inclusive para conservar la armonía en la convivencia. Por otro lado, expone la necesidad de cautelar este conocimiento para que se conserve el orden social: "Pero de ahí a abolir el principio de causalidad en psicoterapia existe una gran diferencia. Sin causalidad en el ámbito de lo psicológico sólo nos resta dedicarnos a otra cosa. En un sentido estricto no podríamos dedicarnos a cosa alguna, dado que la convivencia humana sería caótica." ${ }^{264}$ Entonces, como señala Barnes cualquier cambio en la distribución del conocimiento implica un cambio en la distribución de poderes. ${ }^{65}$

\section{2.- La Psicoterapia Integrativa.}

El Modelo Integrativo, no define quiénes serían objeto de la psicoterapia integrativa, sin embargo, define a ésta, como "un proceso interpersonal orientado intencionalmente al logro de objetivos terapéuticos acordados entre paciente y terapeuta [...] El terapeuta puede 'vo-

${ }^{63}$ BARNES en Op. Cit. 42. Pág. 286.

${ }^{64}$ Op. Cit. 24. Pág. 427.

${ }^{65}$ BARNES en Op. Cit. 42. Pág. 287. 
tar' objetivos del paciente que le parezcan éticamente inaceptables." ${ }^{66}$ De lo anterior podemos deducir que el terapeuta que adscribe a este Modelo, está constantemente contrastando al paciente que tiene al frente, con un modelo de hombre tanto valórico como moral.

Lo anterior es señalado por Foucault, quien sostiene que la práctica clínica no es sólo una agrupación de técnicas de curación y del saber que éstas requieren; sino que también tendrá implícitamente una definición del hombre modelo, "en la gestión de la existencia humana, toma una postura normativa, que no la autoriza simplemente a distribuir consejos de vida prudente, sino que la funda para regir las relaciones físicas y morales del individuo y de la sociedad en la cual él vive." 67

Así, podemos pensar que la Psicoterapia Integrativa -y en general la mayoría de las psicoterapias actuales- está destinada a adaptar a los individuos al modelo de sociedad imperante, por lo tanto, ajustarlos funcionalmente al sistema dominante en nuestros días; el cual define al "hombre", según los intereses económicos, valorativos y de estilo de pensamiento, que permiten perpetuar la estabilidad del sistema. ${ }^{68}$

En la práctica clínica vemos cómo la psicoterapia puede ser "analizada también como una relación de servicios codificado y reglamentada, una relación entre un especialista y un paciente en la que el objeto de reparación es el sujeto enfermo y en la que, como mostró Goffman, el especialista controla el proceso sucesivo de observación, diagnóstico, prescripción y tratamiento. La relación especialista-paciente es una relación socialmente estructurada"69, donde en el proceso terapéutico se va sustituyendo gradualmente el discurso del paciente, que es considerado inadaptado o patológico, por el discurso del terapeuta, el cual tiende a la adaptación y a la salud; es este último discurso el que supuestamente posee una verdad práctica ${ }^{70}$.

${ }^{66}$ Op. Cit. 16. Págs. 145 y ss.

${ }^{67}$ Op. Cit. 4. Pág. 61.

68 "La técnica es en cada caso un proyecto histórico social, en él se proyecta lo que una sociedad y los intereses en ella dominantes tienen el propósito de hacer con los hombres y con las cosas". Op. Cit. 44. Pág. 55.

${ }^{69}$ ALVAREZ-URIA, Fernando. "LA CAJA DE PANDORA: SOCIOLOGÍA DEL CONOCIMIENTO Y PSICOLOGIA CLÍNICA". Revista Clínica y Salud Vol 2 (1), 1991. Págs. 51-6I.

${ }^{70}$ Op. Cit. 1. Pág. 11.
En otras palabras, en la relación terapéutica se establece una relación de poder, donde el terapeuta es el más cercano a la realidad.

Vemos de esta forma cómo en este tipo de psicoterapia, existen algunos elementos, que muy probablemente son compartidos por otras psicoterapias, y que muchas veces, no se hace explícito a la psicología.

\section{3.- El Sujeto en el Modelo Integrativo.}

La noción de sujeto ${ }^{71}$ que erigen en este Modelo no es clara. Primero, intentan establecer un acercamiento entre el Self y el Sujeto ${ }^{72}$ planteando "un concepto cercano al de individuo y habitualmente utilizado es el de sujeto: en epistemología es utilizado como sinónimo de yo"73, luego señalan que "el Self recoge está condición de singularidad propia del individuo/ sujeto, pero no se reduce a estos conceptos, por otro lado, el concepto de persona incluye el sí mismo pero no se identifica con él. La persona es un universal cultural, mientras que los sí mismos pueden presentar diferentes formas." 74

En ambas afirmaciones podemos ver que no existe una claridad en el propio concepto de Self y aunque se intenta relacionar con el concepto de Sujeto, no se pone de manifiesto cual sería esta relación, ni qué entienden por Sujeto. Esto es concordante con la autocrítica que realiza Opazo, cuando señala "que el concepto de sistema Self es vulnerable también a la crítica dura. Está insuficientemente explicitado; si bien se han delimitado satisfactoriamente los pilares básicos del sistema Self, hasta ahora sólo han sido parcialmente conectados entre sí. Es así como las diferentes funciones del Self aparecen más bien como yuxtapuestas, insuficientemente integradas." 75

\footnotetext{
${ }^{71}$ Los autores adscriben a la visión de sujeto planteada por la Teoría Crítica: "la práctica constructiva de los conceptos es, de manera predominantemente social y está regida por leyes que presiden el desenvolvimiento de esas totalidades $u$ organismos sociales. Para estas dos concepciones tanto los términos teóricos como los empíricos, surgen de, y expresan la experiencia del sujeto social". SAMAJ, Juan. "EPISTEMOLOGÍA Y METODOLOGÍA. ELEMENTOS PARA UNA TEORÍA DE LA INVESTIGACIÓN CIENTÍFICA". Editorial Universitaria. Buenos Aires, 1997. Pág. 95.

${ }^{72}$ ILLANES, Cecilia y TIRADO Juan. "El SELF EN LA PSICOTERAPIA Integrativa". Tesis para optar al titulo de especialista en psicoterapia Integrativa ICPSI, 2002.

${ }^{73}$ Op. Cit. 73. Pág. 13.

${ }^{74}$ Op. Cit. 73. Pág. 14.

${ }^{75}$ Op. Cit. 16. Pág. 341.
} 


\section{MARTÍNEZ, QUINTEROS}

No obstante, el Self descrito es un sistema que recibe influencias en el proceso de significación, tanto desde fuera, como desde dentro. Desde fuera recibe los estímulos externos del medio y desde dentro "los subsistemas o paradigmas influyen y 'presionan' al sistema Self a procesar de determinada forma." ${ }^{, 76}$ Por otra parte, el sistema Self cumple las funciones de identidad, de auto-organización, de significación, y de control conductual. "El sistema psicológico opera en torno al Self, el cual constituye un principio organizador e integrador de los subsistemas y de la experiencia."77

De lo anterior, podemos inferir que el Self del Modelo Integrativo, posee una naturaleza funcional, que organiza, procesa y actúa en relación a la estimulación que recibe tanto del medio, como desde lo interno; es decir, el Self existe en la medida que cumple un rol en el Modelo Integrativo, ayudando a comprender mejor el funcionamiento de la persona, y la psicoterapia entonces, estaría destinada a logra un mejor funcionamiento del Self. ${ }^{78}$

De esta manera el Self queda definido por las tareas que cumple y la calidad con que ejecuta sus funciones, lo categorizarán como un buen o mal Self. Asimismo, se deja de lado otro tipo de características o definiciones, que no estén orientadas al quehacer práctico, recortando de esta manera toda pretensión de un conocimiento más global y profundo de su Sujeto.

El Modelo Integrativo, nos muestra un Self en partes interrelacionadas, haciéndose dificultoso poder vislumbrar el todo; por lo tanto, es difícil lograr configurar la noción de individuo que está a la base en este Modelo, más bien sólo se muestran partes funcionales de éste, lo que podría ser un reflejo del espíritu de nuestros tiempos. El individuo poseedor, que nuestra sociedad ha puesto en el centro de todas las relaciones sociales es un individuo calculador, que calcula sus intereses materiales en función de su consumo y de la acumulación de posibilidades, puede considerarse a sí mismo con su cuerpo y alma como capital suyo. Todas sus habilidades y hasta todo su prestigio ahora lo puede emplear como capital en la persecución calculada de sus intereses y de cualquier chance de

\footnotetext{
${ }^{76}$ Op. Cit. 16. Pág, 122.

77 Op. Cit. 24. Pág. 472.

${ }^{78}$ Opazo señala "que cualquier cambio clínico significativo implicará algún cambio en el sistema Self". Op. Cit. 16. Pág. 146.
}

acceder a algo. ${ }^{79}$ Por esto la funcionalidad es tan importante para el Modelo, pues permite al individuo una mejor administración de sus propios recursos y busca mejorar sus funcionamientos para ampliar sus posibilidades de satisfacer sus necesidades.

En este sentido, Molinari señala "en el curso de la historia de la psicología se han sucedido diferentes modos de comprender ese objeto complejo que es el hombre. La psicología ha producido diferentes modelos de hombre, los que a su vez han alimentado la creación de diferentes psicotecnologías." 80

En todo caso, este hombre, sea cual sea su naturaleza en este Modelo, está escindido de lo social, o del sujeto trascendental ${ }^{81}$ o general, ya que no lo alude en relación a otros, excepto al considerar al otro como una mera fuente de estímulos. Tampoco hace referencia a la sociedad en la cual está inserto el individuo, ni ve al individuo reflejado en su sociedad; por lo tanto, podría perder la perspectiva de que el individuo puede observarse en los otros, entendiendo al otro como lo otro de sí. ${ }^{82}$

${ }^{79}$ HINKELAMMERT, Franz J. "LA VUELTA DEL SUJETO HUMANO REPRIMIDO FRENTE A LA ESTRATEGIA DE LA GLOBALIZACIÓN". Revista Pasos N ${ }^{\circ}$ 104 artículo 1, noviembre - diciembre. Segunda época 2002.

${ }^{80}$ Op. Cit. 1. Pág. 6.

${ }^{81}$ El Sujeto "trascendental, constitutivo de toda experiencia de la realidad, es a su vez abstracción del hombre concreto y viviente. Es evidente que el concepto abstracto de Sujeto trascendental (las formas de pensamiento, la unidad de éstas y la productividad originaria de la conciencia) supone lo que pretende fundar: la individualidad real y viviente [...] El Sujeto trascendental, en cierto sentido, es más real, es decir, más determinante para la conducta real de los hombres y para la sociedad formada a partir de ella, que esos individuos psicológicos de los que fue abstraído el Sujeto trascendental, que muy poco pueden hacer en el mundo: se han convertido en meros apéndices de la maquinaria social y, por último, en ideología". ADORNO, Theodor W. "CONSIGNAS". Epilegómenos Dialécticos: Sobre Teoría y Praxis. Editorial Amorrortu. Buenos Aires, 1973. Págs. 145-146.

82 "El binomio [sujeto]-[objeto] que se da en todo proceso de conocimiento se despliega, para las ciencias naturales, como [sujeto (sujeto-objeto)]-[objeto] y, para las ciencias sociales, como [sujeto (sujeto-objeto)]-[objeto (sujeto-objeto)]". El segundo paréntesis, relación interna dentro del segundo término de la relación psicología-sociedad, es lo que distingue especialmente a la sociedad como realidad reflexiva y a la psicología como ciencia reflexiva. ENGUITA, Mariano F. "SUJETO, OBJETO Y REFLEXIVIDAD”, en ÁLVAREZ-URÍA, F. JESƯS IBÁÑEZ: TEORÍA Y PRÁCTICA. Madrid, Endimión, 1997. Págs. 317-332. 
Como señala Adorno, "los seres humanos no son capaces de reconocerse a sí mismos en la sociedad, ni ésta en ellos, porque están enajenados entre sí y respecto del conjunto." ${ }^{83}$ Sin embargo, la separación entre psique y sociedad "es falsa conciencia; eterniza en forma de categorías la escisión entre el sujeto viviente y la objetividad que impera sobre los sujetos y que, no obstante, son ellos quienes la producen." 84

Por otra parte, el Modelo no identifica al terapeuta como constructor de una realidad social ${ }^{85}$-esto no es mencionado en la literatura del Modelo- en esta realidad no existe una neutralidad al momento de realizar esta construcción. Como señala Fruggeri "los sistemas de creencias vinculados con la práctica del terapeuta, y la manera en que éste coordina sus acciones con las del cliente, no pueden en modo alguno darse por supuesto. Además, tampoco pueden seguir siendo invisibles" ${ }^{\text {, }}$, coincidimos en que "la psicoterapia no se puede abstraer del contexto social que la determina y dentro del cual tiene lugar." 87

Por lo tanto, una Psicología "que no quiere oír hablar de la sociedad, y que se empeña idiosincráticamente en el individuo y sus herencias arcaicas" ${ }^{\$ 8}$, proyecta más una fatalidad social que una Psicología que, tome en cuenta $l a$ realidad social, con una aproximación más integral al Sujeto. Por el contrario, una psicología en búsqueda de la objetividad "arroja a los sujetos de vuelta a sus limitados sí mismos, y pone ante ellos una imagen de espejo de su escindido ser para sí, el sujeto monadológico y su psicología, como si fuera su esencia." 89

Así la ciencia en que esperaba encontrarse a los sujetos, los transforma en objetos y la psicología que busca un interior autónomo respecto al exterior, se convierte en enfermedad "en una

${ }^{83}$ ADORNO Theodor W. "ACTUALIDAD DE LA FILOSOFÍA”. Editorial Paidós. Madrid, 1996. Pág. 139.

${ }^{84}$ Op. Cit. 84. Pág. 139.

85 "Los intelectuales dedicados a las ciencias sociales han estado tan ocupados en el examen de la conducta de los demás, que olvidaron en gran medida estudiar sus problemas, su situación y su conducta propios, evitando así examinar nuestras propias creencias como ahora examinamos las de los demás". Op. Cit. 84. Págs. 317-332.

${ }^{86}$ FRUGGERI en MC NAMEE Sheila y GERGEN Kenneth. "LA TERAPIA COMO CONSTRUCCIÓN SOCIAL”. Editorial Paidós. Buenos Aires, 1996. Pág. 68.

${ }^{87}$ FRUGGERI en Op. Cit. 87. Pág. 69.

88 Op. Cit. 84. Pág. 140.

${ }^{89}$ Op. Cit. 84. Pág. 154. sociedad que lo busca sin descanso: a partir de ahí entra en posesión de su herencia la psicoterapia." ${ }^{90}$ Es más, "el psicologicismo en cualquiera de sus figuras, el individuo como punto de arranque sin más especificaciones, es ideología. Transforma por ensalmo la forma individualista de socialización en definición extrasocial, natural del individuo."

\section{4.- Conclusiones}

Creemos que el tipo de razonamiento utilizado en esta práctica clínica está sostenido en la razón instrumental, desde la cual lo importante es obtener logros y alcanzar metas, olvidándose de una razón más amplia, que nos muestre qué es lo que pasa alrededor de esta práctica; siendo muy importante la técnica eficaz, por sobre la reflexión, debido a la urgencia de dar soluciones reales a la personas.

Sin embargo, el científico social, lo quiera o no, "aunque raramente de la manera en que quiere, si es que lo quiere, influye sobre su objeto, la sociedad, tanto en el proceso de producción del conocimiento como con la difusión del conocimiento producido. En el acto de investigación por cuanto que, de un modo u otro, transmite sus expectativas al objeto investigado." ${ }^{\prime 92}$

Podemos pensar que en esta forma de mirar, la práctica clínica pierde al sujeto, ya que omite la mediación que existe entre los sujetos particulares y el sujeto transcendental, al separarlos y quedarse sólo con los sujetos particulares, los transforma en individuos porque se ha perdido la conciencia de que el ser uno mismo es posible solamente al ser con los otros, esta pérdida de conciencia nos entrega a individuos cosificados. ${ }^{93}$

En las implicancias de esta relación, se evidencia que el concepto de sujeto sano ${ }^{94}$ en psicología, participará en la determinación de quién debe ser objeto de las prácticas clínicas y también delimitará el accionar de éstas, es decir, determinará cuándo se ha sanado a la persona o cuáles son las problemáticas que deben ser abordadas en su quehacer.

\footnotetext{
${ }^{90}$ Op. Cit. 84. Pág. 155.

${ }^{91}$ Op. Cit. 84. Pág. 157.

${ }^{92}$ Op. Cit. 84. Págs. 317-332.

${ }^{93}$ DUFOUR, Dany-Robert. "LOS DESCONCIERTOS DELINDIVIDUO-SUJETO”. Le Monde Diplomatique, Edición Cono Sur, 11 de Mayo N² 23, 2001.

94 "Las tradiciones en psicología clínica no son conjuntos de enunciados que compiten por la representación más fiel de la realidad, sino maneras culturalmente ancladas de construir la mente o el psiquismo". Op. Cit. 1. Pág. 6.
} 


\section{MARTÍNEZ, QUINTEROS}

Esta concepción de sujeto de la psicología, define el deber hacer del terapeuta, guiando su labor en la dirección, ya sea de tomar conciencia, modificar o sólo adaptar a quienes concurren a sus terapias. A su vez, también el quehacer favorece la instauración o permanencia de un determinado modo de vivir "la psicología clínica misma puede intervenir en la creación de nuevas formas de la sociedad y la cultura, y por eso es necesario que cultive su reflexividad respecto de sus producciones: ¿qué se privilegia y qué se relega en los modos en que la disciplina configura discursivamente el mundo?, ¿quién gana y quién pierde, qué políticas o instituciones son favorecidas y cuáles son perjudicadas?"9s, entonces si es que nuestras conceptualizaciones favorecen ciertos modos de vida por sobre otros, es necesario hacer la reflexión sobre ello, permitiendo la "insurrección de los saberes sometidos." 96

El psicólogo, debe reajustar permanentemente sus técnicas de investigación y aún su concepción del objeto investigado para tomar en cuenta los efectos de la producción y distribución del conocimiento psicológico, intentando superar los esquemas predelimitados por la disciplina, tanto aquellos implícitos como explícitos, con el objeto de volver a las raíces donde la tekhne iatriké, implicaba "un saber hacer, sabiendo por qué se hace lo que se hace."97

\section{Referencias}

Adorno Theodor W. "Actualidad De La Filosofia". Editorial Paidós. Madrid, 1996.

Adorno, Theodor W. "Consignas". Epilegómenos Dialécticos: Sobre Teoría y Praxis. Editorial Amorrortu. Buenos Aires, 1973.

Álvarez-Uria, Fernando. "La Caja De Pandora: Sociología Del Conocimiento Y Psicología Clínica”. Revista Clínica y Salud Vol 2 (1), 1991.

Brunet, Ignasi Y Valero, Luis. "Epistemología Y Sociología De Las Ciencias”. Promoción y publicaciones Universitarias S.A. Barcelona, 1996.

Diéguez, Antonio J. "Cientifismo Y Modernidad: Una Discusión Sobre El Lugar De La Ciencia”. Revista

${ }^{95}$ Op. Cit. 1. Pág. 13.

${ }^{96}$ Entendiendo éstos, por una parte, como los contenidos históricos que han estado sepultados, enmascarados en el interior de coherencias funcionales, ó por otra parte como una serie de saberes calificados como incompetentes, o insuficientemente elaborados.

Op. Cit. 41. Págs. 128 y 129.

${ }^{97}$ VALDÉS-STABER, Juan. "PLURALIDAD METODOLÓGICA EN PSIQUIATRÍA". Revista Psicothema, Vol. 12, Supl. N², 2000. Pág. 545.
Interdisciplinaria de Filosofía "El Giro Postmoderno". Suplemento 1, 1993.

Dufour, Dany-Robert. "Los Desconciertos Del Individuo Sujeto". Le Monde Diplomatique, Edición Cono Sur, 11 de mayo $\mathrm{N}^{\circ} 23,2001$.

Enguita, Mariano F. "Sujeto, Objeto Y Reflexividad", En Alvarez-Uría, F. Jesús Tbáñez: Teoría Y Práctica. Madrid, Endimión, 1997.

Foucault, Michel. "El Nacimiento De La Clínica, Una Arqueología De La Mirada Médica". Traducción de Francisca Penjo. Editorial Siglo XXI. México, 1996.

Foucault, Michel. "La Historia De La Locura". Editorial Fondo de Cultura Económica. México, 1998. Volumen I.

Foucault, Michel. "Microfisica Del Poder", Ediciones de la Piqueta. Madrid, 1992.

Fruggeri En Mc Namee Sheila Y Gergen Kenneth. "La Terapia Como Construcción Social”. Editorial Paidós. Buenos Aires, 1996.

Habermas, Jürgen. "Ciencia Y Técnica Como Ideología". Editorial Tecnos S.A. Madrid, 1999.

Hinkelammert, Franz J. "La Vuelta Del Sujeto Humano Reprimido Frente ALa Estrategia De La Globalización". Revista Pasos No 104 artículo 1, noviembre-diciembre. Segunda época 2002.

Illanes, Cecilia Y Tirado Juan. "El Self En La Psicoterapia Integrativa". Tesis para optar al título de especialista en psicoterapia Integrativa ICPSI, 2002.

Kendall, Philip Y Norton-Ford, Julian. "Psicología Clínica”. Editorial Limusa S.A. Cuidad de México, 1988.

Klimovsky G., "Las Desventuras Del Conocimiento Científico (Una Introducción A La Epistemología)". A-Z Editora, Buenos Aires, 1994.

Kuhn, T. S. "La Estructura De Las Revoluciones Cientificas". Fondo de Cultura Económica Chile S.A. Santiago de Chile, 1993.

Laplanche, Jean Y Pontalis Jean-Bertrand. "Diccionario De Psicoanálisis". Editorial Piados SAICF. Buenos Aires, 2001.

Matus, Teresa. "Propuestas Contemporáneas En Trabajo Social, Hacia Una Visión Polifónica”. Editorial Espacio. Buenos Aires. Argentina, 1999.

Molinari, Juan M. "Psicología Clínica En La Posmodernidad: Perspectivas Desde El Construccionismo Social". Revista Psykhe. Vol 12 (1). 3-15, 2003.

Opazo, Roberto. "Integración En Psicoterapia". Ediciones CECIDEP. Santiago de Chile, 1992.

Opazo, Roberto. "Psicoterapia Integrativa. Delimitación Clínica”. Ediciones ICPSI. Santiago de Chile, 2001.

Perez-Tamayo, Ruy. "El Ejercicio Actual De La Medicina". Consejo de Salubridad General, México, 1996-2003. Consultado en octubre, 25, 2003 en http// www.salud.gob.mx/unidades/csg/ publica/libros/ejercicio/.html.

Popper, Karl. "El Desarrollo Del Conocimiento Científico. Conjeturas Y Refutaciones". Ediciones Paidós, Buenos Aires, 1964.

Prieto, Pablo (2003). "Arte". Consultado en octubre 29, 2003, en: http://www.almudi.org/App/Asp/Noticias/ noticias.asp? $\mathrm{n}=414$.

Roca I Sebastiá, Françesc. “¿Es La Psiquiatría Una Ciencia?" Revista de la Asociación Española de Neuropsiquiatría Vol. 19 (72), 1999.

Samaj, Juan. "Epistemología Y Metodología. Elementos Para Una Teoría De La Investigación Científica”. Editorial Universitaria. Buenos Aires, 1997.

Valdés-Staber, Juan. "Pluralidad Metodológica En Psiquiatría”. Revista Psicothema, Vol. 12, Supl. N², 2000. 